\title{
Playing tennis in hot environment: Applied strategies and new directions
}

\author{
Nicolas Robin ${ }^{a} \mathbb{D}$, Laurent Dominique ${ }^{b}$ \& Guillaume R. Coudevylle
}

aUniversité des Antilles. 'Université de la Réunion.

\begin{abstract}
Many tennis competitions are held in hot ambient conditions, which can negatively affect endurance, mental and cognitive functioning and/or motor performance. The purpose of this article is to take stock of the physical techniques and psychological strategies that tennis players can use to counteract the negative effect of the heat. In addition, a new direction based on the mindfulness technic is proposed in this article.
\end{abstract}

Key words: tennis, heat, strategies, cooling, attention, performance

Received: 2 February 2021

Acepted: 10 March 2021

Corresponding author: Nicolas Robin. Laboratoire ACTES (UPRES 3596), UFR STAPS de Guadeloupe, Université des Antilles Email: robin.nicolas@hotmail.fr

\section{INTRODUCTION}

Performing a sport such as tennis in the heat is physically demanding due to reduced neuromuscular function, increased individual's core temperature, altered skeletal muscle metabolism and increased cardiovascular strain due to thermoregulation (Douzi, Dupuy, Theurot, Smolander, \& Dugué, 2020; Nybo, Rasmussen, \& Sawka, 2014). Moreover, because of the heat, psychological strain via arousal (Nielsen, Hyldig, Bidstrup, Gonzalez-Alonso, \& Christoffersen, 2001), reduced motivation (Bridge, Weller, Rayson, \& Jones, 2003), increase in negative affects (Gaoua, Grantham, Racinais, \& El Massioui, 2012) and decrease in positive affects (Robin et al., 2019) can negatively influence sport performance. Indeed, the latter authors showed that a hot environment can decrease athletes' accuracy in a task requiring concentration. Finally, heat stress can promote the appearance of peripheral muscle fatigue during prolonged aerobic exercise (Crewe, Tucker, \& Noakes, 2008) and the early onset of mental fatigue when performing highly cognition-demanding attention task (Qian et al., 2015). Attentional processes are very important components of successful performance in tennis. However, as the level of stress due to heat, athlete's temperatures and game complexity increase, attentional resources are progressively drained. It seems therefore important to use strategies that allow better regulation and better adaptation to the hyperthermia, induced by exercising, and the decrease in attention functioning caused by the heat (Coudevylle, Sinnapah, Robin, Collado, \& Hue, 2019). Racinais et al. (2015) argued that physically active acclimation (e.g., from 5 to 14 days before competition) under heat stress is the "most important intervention one can adopt to reduce physiological strain, optimize performance (during training and competition in the heat) and reduce the risk of serious heat illness." In addition, fluid ingestion is really important because hot environments lead to increased sweating caused by physiological thermoregulatory processes (Schlader, Simmons, Stannard, \& Mundel, 2011) that induce dehydration that is accentuated during exercise (Ando et al., 2015). Moreover, cooling can be efficient strategies for tennis players performing in the heat before (pre-), during (per-), and/or post match (post-cooling) as illustrated in Figure 1.

\section{Before competition}

During match

Between matches and/or at the end of competition

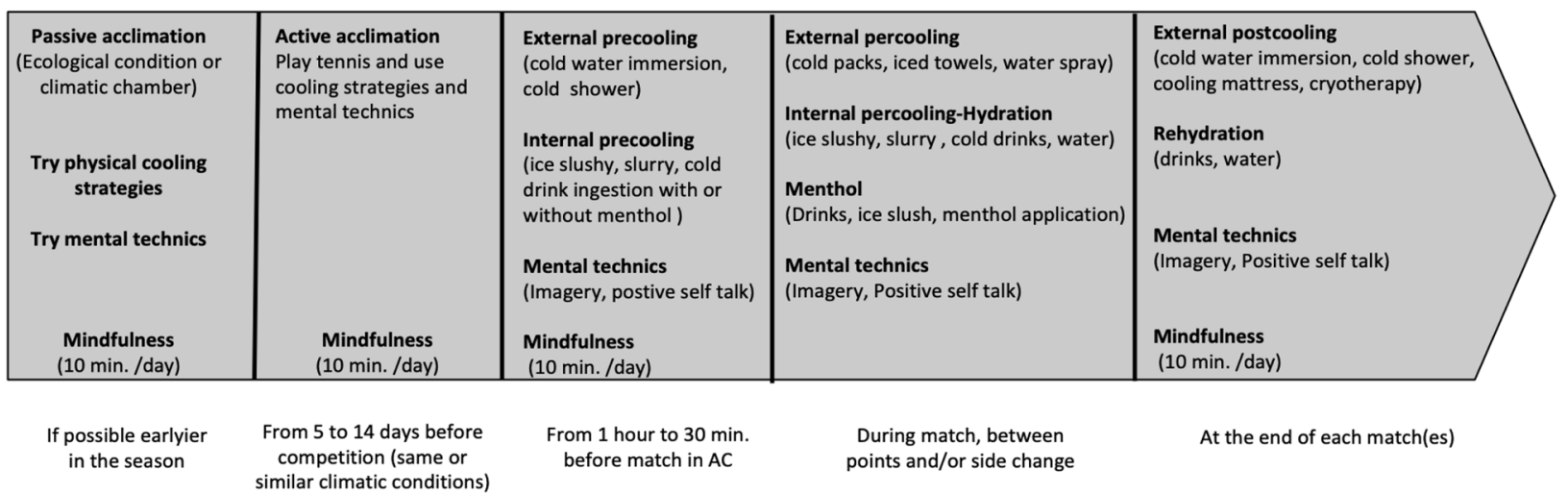

Figure 1. Examples of strategies that tennis players can use in the heat 
Cooling strategies are generally classified as internal (e.g., ice slushy, slurry, cold drink ingestion with or without menthol) or external strategies (e.g., cold water immersion, cooling vest or garments, ice towels, neck cooling, cool showers, cold pack, menthol application or water spray), that have been shown to reduce core and skin temperatures, that can improve performances in athletes performing in the heat (Douzi et al., 2020).

Recently, Coudevylle and collaborators (2019) evoked that the use of mental or psychological skills training can improve cognitive and motor performances in the heat. For example, Barwood, Thelwell, and Tipton (2008) showed that a training set of four psychological skills (positive selftalk, mental imagery, goal setting, and arousal regulation) increased motor performance (90-minute "time trials") in a hot environment. Positive or motivational self-talk is a top-down regulation strategy that requires tennis players to continuously re-appraise negative self-talk with selfcontextualized motivational and instructional statements that include cue aiming and focusing or directing attention such as 'focus on the ball trajectory', technique, strategy, and kinesthetic attributes of a skill. Positive self-talk, used in hot environment, can help tennis players to actively reformulate negative statements (e.g., 'I'm tired', 'I'm going to stop, it's too hot') to motivational and positive statements (e.g., 'I can do it', 'It's not so hot, I can play and win').

For example, using a two weeks motivational self-talk intervention, Wallace et al. (2017) showed motor (endurance capacity) and cognitive (working memory, attention, speed processing) task performance improvements in the heat. Finally, researchers recently evoked the potential beneficial effect of mindfulness in sports performed in the heat (Coudevylle et al., 2019). Mindfulness corresponds to a state of awareness and attention to the present moment, which includes attention to environmental, mental, and physical stimuli without making evaluations. This mental technic, which is composed of three components: 'Awareness' of current emotions, bodily sensations, and thoughts, non-judgmental 'acceptance', and 'commitment' to goal-relevant attention focus and behaviour, is frequently used by athletes including tennis players. Haase et al. (2015) found that mindfulness intervention changed the way athletes' process interoceptive afferent informations and improved their ability to regulate anxiety related to unpleasant though, sensation and feelings.

The relation between mindfulness and tennis performance could refer to sense of control over oneself and the heat, and to the altering perceptions of barriers or distractions that would potentially concerned heat stress and its consequences such as fatigue or thermal discomfort (Coudevylle et al., 2019).

\section{CONCLUSION}

Heat stress and the hyperthermia caused by playing tennis in the heat induce physiological and cognitive (e.g., attentional) strains that can degrade tennis performance and leading to potential risks for the players performing in hot ambient conditions. The use of strategies to counteract the effects of heat stress on tennis player performance seems therefore to be necessary. Active acclimation, cooling intervention, acute hydration, or positive motivational self-talk seem to be interesting strategies to explore in order to counteract the negative influence of the heat (increase of fatigue, thermal discomfort, decrease in motivation and concentration) and

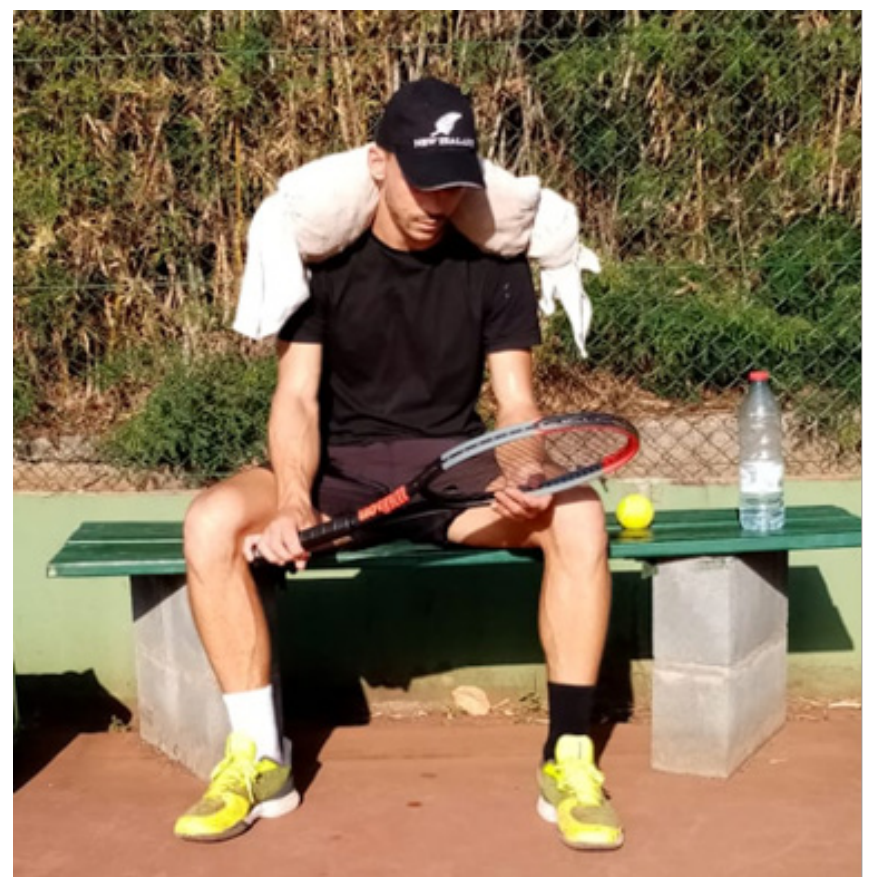

lower the perceived load of high temperature. Finally, the use of mindfulness, which can benefit attentional processes, could be potentially useful during tennis training and competitions performed in hot environment.

\section{REFERENCES}

Ando, S., Komiyama, T., Sudo, M., Kiyonaga, A., Tanaka, H., \& Higaki, Y. (2015). The effects of temporal neck cooling on cognitive function during strenuous exercise in a hot environment: A pilot study. BMC Research Notes, 8, 202-210. https://doi.org/10.1186/s13104-015-1210-0

Barwood, M. J., Thelwell, R. C., \& Tipton, M. J. (2008). Psychological skills training improves exercise performance in the heat. Medicine and Science in Sports and Exercise, 40(2), 387-396. https://doi.org/10.1249/mss.0b013e31815adf31

Bridge, M. W., Weller, A. S., Rayson, M., \& Jones, D. A. (2003). Responses to exercise in the heat related to measures of hypothalamic serotonergic and dopaminergic function. European Journal of Applied Physiology, 89(5), 451-459. https://doi.org/10.1007/s00421-003-0800-z

Coudevylle, G. R., Sinnapah, S., Robin, N., Collado, A., \& Hue, O. (2019). Conventional and alternative strategies to cope with the tropical climate of Tokyo 2020. Frontiers in Psychology, 10, 1279. https://doi.org/10.3389/fpsyg.2019.01279

Crewe, H., Tucker, R., \& Noakes, T. D. (2008). The rate of increase in rating of perceived exertion predicts the duration of exercise to fatigue at a fixed power output in different environmental conditions. European Journal of Applied Physiology, 103(5), 569-577. https://doi.org/10.1007/s00421-008-0741-7

Douzi, W., Dupuy, O., Theurot, D., Smolander, J., \& Dugué, B. (2020). Percooling (using cooling systems during physical exercise) enhances physical and cognitive performances in hot environments. A Narrative Review. International Journal of Environmental Research and Public Health, 17, 1031. https://doi.org/10.3390/ijerph17031031

Gaoua, N., Grantham, J., Racinais, S., \& El Massioui, F. (2012). Sensory displeasure reduces complex cognitive performance in the heat. Journal of Environmental Psychology, 32(2), 158-163. https://doi.org/10.1016/j.jenvp.2012.01.002

Haase, L., May, A. C., Falahpour, M., Isakovic, S., Simmons, A. N., ... \& Paulus, M. P. (2015). A pilot study investigating changes in neural processing after mindfulness training in elite athletes. Frontiers in Behavioral Neuroscienve, 9, 229. https://doi.org/10.3389/fnbeh.2015.00229

Nielsen, B., Hyldig, T., Bidstrup, F., Gonzalez-Alonso, J., \& Christoffersen, G. R. (2001). Brain activity and fatigue during prolonged exercise in the heat. Pflugers Archiv, 442(1), 41-48. https://doi.org/10.1007/s004240100515

Nybo, L., Rasmussen, P., \& Sawka, M. N. (2014). Performance in the heat-physiological factors of importance for hyperthermiainduced fatigue. Comprehensive Physiology, 4(2), 657-689. https://doi.org/10.1002/cphy.c130012 
Qian, S., Li, M., Li, G., Liu, K., Li, B., ... \& Sun, G. (2015). Environmental heat stress enhances mental fatigue during sustained attention task performing: Evidence from an ASL perfusion study. Behavioral Brain Research, 280, 6-15. https://doi.org/10.1016/j.bbr.2014.11.036

Racinais, S., Alonso, J. M., Coutts, A. J., Flouris, A. D., Girard, O., ... \& Périard, J. D. (2015). Consensus recommendations on training and competing in the heat. Scandinavian Journal of Medicine and Science in Sports, 25, 6-19. https://doi.org/10.1111/sms.12467

Robin, N., Collado, A., Sinnapah, S., Rosnet, E., Hue, O., \& Coudevylle, G. R. (2019). The influence of tropical climate on cognitive task performance and aiming accuracy in young international fencers. Journal of Human Performance in Extreme Environments, 15(1), 4. https://doi.org/10.7771/2327-2937.1110
Schlader, Z. J., Simmons, S. E., Stannard, S. R., \& Mundel, T. (2011). The independent roles of temperature and thermal perception in the control of human thermoregulatory behavior. Physiology \& Behavior, 103(2), 217224. https://doi.org/10.1016/j.physbeh.2011.02.002

Wallace, P., McKinlay, B., Coletta, N., Vlaar, J., Taber, M., Wilson, P., \& Cheung, S. (2017). Effects of motivational self-talk on endurance and cognitive performance in the heat. Medicine and Science in Sports and Exercise, 49(1), 191-199. https://doi.org/10.1249/MSS.0000000000001087

Copyright (c) 2021 Nicolas Robin, Laurent Dominique \& Guillaume R. Coudevylle

\section{(c) (i)}

This text is under a Creative Commons BY 4.0 license

You are free to Share - copy and redistribute the material in any medium or format - and Adapt the content - remix, transform, and build upon the material for any purpose, even commercially under the following terms:

Attribution: You must give appropriate credit, provide a link to the license, and indicate if changes were made. You may do so in any reasonable manner, but not in any way that suggests the licensor endorses you or your use. 